\title{
MNREGA'S CONTRIBUTION IN JOB CREATION - AN ANALYSIS (WITH SPECIAL REFERNCE TO RUDRPUR DEVELOPMENT BLOCK, DISTRICT UDHAMSINGH NAGAR)
}

\author{
CHANDRA PAL \\ Department of Commerce, Government Degree College Sitarganj, Udham Singh Nagar, Uttarakhand \\ *Corresponding Author Email: cpcommerce1984@gmail.com
}

Received: 1.12.2020; Revised: 11.12.2020; Accepted: 24.12.2020

(C)Society for Himalayan Action Research and Development

\begin{abstract}
Most of the population in India lives in rural settings. There are roughly six lacs and thirtyeight thousands villages where employment could not be generated due to non utilization of natural resources. As most of the population depends on agriculture, the tendency of unemployment is mostly visible.Viewing the problem of unemployment and lack of basic facilities for a common folk, the Goverment of India launched a scheme on 2nd February, 2006 from Anantpur District in Andhra Pradesh, which can provide limited employment. The scheme was named as Mahatma Gandhi National employment Guarentee Scheme (MNREGA). Under this scheme more than 5 lacs people get employment. In the present communiation an attempt has been made to analyse the contribution of MNREGA scheme in employment generation in Rudrpur development Block in District Udhamsinghnagar in Uttarakhand.
\end{abstract}

Keywords: Employment Generation, Rural unemployment, MNREGA, Skill Development

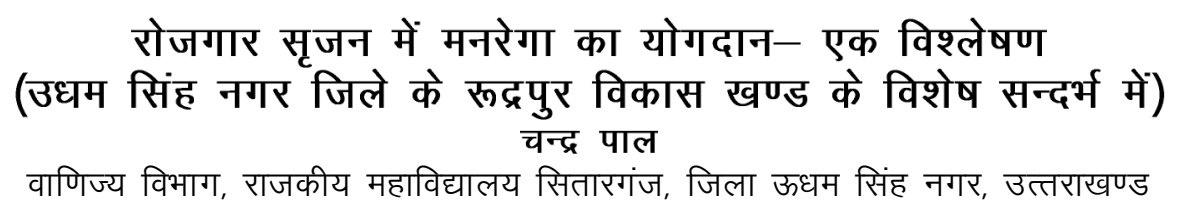

सारांश

भारत की अधिकांश जनसंख्या गावों में निवास करती है। भारत में लगभग 6 लाख 38 हजार गांव हैं। यहां प्राकृतिक संसाधनों का विदोहन नहीं होते के कारण पर्याप्त रोजगार अवसरों का सृजन नहीं हो पाता। इससे श्रमशक्ति का दबाव कृषि पर पड़ता है। चूंकि अधिकांश लोग कृषि पर निर्भर होते हैं। कृषि पर अत्यधिक निर्भरता के कारण गांवों में अदृश्य बेरोजगारी तथा मौसमी बेरोजगारी की प्रवृत्ति अधिक देखने को मिलती है। आधारभूत सुविधाओं और बेरोजगारी की समस्या को दृष्टिगत रखते हुए तत्कालीन भारत सरकार ने ग्रामीण क्षेत्रों का आर्थिक विकास करने और ग्रामीण को रोजगार के अतिरिक्त अवसर देने हेतु 2 फरवरी 2006 को महात्मा गांधी राष्ट्रीय ग्रामीण रोजगार गारण्टी योजना (मनरेगा) का प्रारम्भ आन्ध्र प्रदेश के अनन्तपुर जिले से किया। इसका प्रमुख लक्ष्य ग्रामीणों की आजीविका को सुरक्षित कर अतिरिक्त आय के अवसरों में वृद्वि करना है। मनरेगा में 5 लाख से भी अधिक लोगों को सालाना रोजगार मिलता है। वर्ष 2020-21 में अब तक 295.84 करोड़ मानव दिवसों का सृजन हो चुका है। वर्तमान में इसके कुल लाभार्थियों की संख्या 28.56 करोड़ है। मनरेगा ने पंजीकृत ग्रामीण परिवार को 100 दिन की रोजगार की गारण्टी देकर रोजगार सृजन की दिशा में एक ऐसी मिशाल पेश की है, जिससे 
Himalayan J. Soc. Sci. \& Humanities ISSN: 0975-9891

Vol. 15, (2020) 63-71

DOI: https://doi.org/10.51220/hjssh.v15i1.9

बेरोजगारी कम करके गरीबी दूर करने में मदद मिल रही है। प्रस्तुत शोधपत्र के माध्यम से रोजगार सृजन में मनरेगा के योगदान को उधम सिंह नगर जिले के रूद्रपुर विकास खण्ड के विशेष सन्दर्भ मे जानने का प्रयास किया गया है।

कुंजी शब्द - रोजगार सृजन, ग्रामीण बेरोजगारी, मनरेगा, कौशल विकास।

भारत गांवों का देश है। ग्रामीण क्षेत्रों में आर्थिक विकास की उपेक्षा न तो सम्भव है और न ही न्यायोचित। शहरी क्षेत्रों का विकास भी प्रत्यक्ष और अप्रत्यक्ष रूप से ग्रामीण विकास पर निर्भर करता है। 2011 की जनगणना के अनुसार यहां की लगभग 68.8 प्रतिशत जनसंख्या गांवो में निवास करती है। प्राकृतिक संसाधनों से धनी भारत में विकास की अपार सम्भावनाएं रहते हुए भी बेरोजगारी और गरीबी की समस्या से जुड़ा रहा है। भारत में बेरोजगारी का मुख्य कारण गरीबी है। गरीबी या निर्धनता का अर्थ उस स्थिति से है, जिससे समाज या व्यक्ति जीवन की बुनियादी आव यकताओं को सन्तुष्ट करने में असमर्थ रहता है। आजादी के 73 सालों से निरन्तर इस दिशा में अनेक योजनाओं तथा विकास कार्यक्रमों को प्रारम्भ किया गया, किन्तु समस्या पहले से अधिक विकट होती जा रही है। 1996 में विश्व बैंक की मानव विकास रिपोर्ट में कहा गया है कि "भारत रोजगार विहीन विकास के पदक्रम में पहुंचने का गौरव प्राप्त कर चुका है। यहां बेरोजगार बड़ी मात्रा में रहते हैं। ग्रामीण क्षेत्र में बेरोजगारी शहरी क्षेत्र की अपेक्षा अधिक है।"

देश में रोजगार की समस्या के अनेक आयाम है। अब तक बंटवारा शारीरिक एवं बौद्धिक रूप से होता था। सन् 1986 में नयी शिक्षा नीति ने पढ़ाई-लिखाई को मुख्यतया रोजगारन्मोमुख शिक्षा का रूप देकर शिक्षित बेरोजगारों पर केन्द्रित कर दिया। फिर कुशल अकुशल के बीच श्रम के विभाजन की परिपाटी ब्रिटिशकाल से चली आ रही है। काम चाहने वाले की अपनी योग्यतानुसार कार्य न मिलने की स्थिति भी बेरोजगारी का अन्य रूप रहा है। देश में एक ऐसा वर्ग भी है, जो यह मानकर चलता है, कि किसान वर्ष में मात्र 147 से 156 दिन काम करता है। अपनी इसी समझ के अनुसार यहां किसानों और उसके परिवार के श्रम मूल्य का आंकलन कृषि लागत में जोड़कर, उसे हकदारी से वंचित रखने की परिपाटी चल रही है। ${ }^{1}$ कृषि कार्यों तथा उसकी सहायक क्रियाओं में आवश्यकता से अधिक श्रमशक्ति कार्यरत है। जिसकी उत्पाद क्षमता शून्य या कभी-कभी ऋणात्मक हो जाती है। कृषि पर आवश्यकता से अधिक सदस्य निर्भर हैं। बेरोजगारी, गरीबी से उत्पन्न होती है। गरीबी से शिक्षा, स्वास्थ्य, पोषण, कार्यकुशलता आदि प्रभावित होती है। लोगों में गुणात्मक तथा मात्रात्मक बदलाव तब तक नहीं हो सकते जब तक सभी को रोजगार न मिल जाए। ${ }^{2}$ यह सार्वभौमिक सत्य है कि भारत के ग्रामीण क्षेत्रों में निर्धनता एवं बेरोजगारी की मात्रा आधी है। यह उतनी ही जटिल है जितनी स्वतन्त्रता के समय थी। स्वतन्त्रता प्राप्ति के बाद आर्थिक विकास हेतु जो पंचवर्षीय योजनाओं और योजनाबद्ध विकास कार्यक्रम निर्धारित किए गए। उनकी क्षेत्रों में विकास की गति तो परिलक्षित होती, परन्तु ग्रामीण बेरोजगारी की स्थिति में कोई विशेष सुधार नहीं हुआ। रोजगार की स्थिति अच्छी नहीं होने के कारण भारतीय अर्थव्यवस्था को रोजगार विहीन आर्थिक विकास की संज्ञा दी गई। आधारभूत सुविधाओं और रोजगार के अभाव में गांवो से निरंतर शहरों की ओर पलायन हो रहा है, परिणामस्वरूप गांव खाली हो रहे हैं। इसी समस्या को दृष्टिगत रखते हुए केन्द्र सरकार ने अपनी महत्वाकांक्षी राष्ट्रीय ग्रामीण रोजगार योजना का शुभारम्भ तत्कालीन प्रधानमंत्री डा० मनमोहन सिंह जी ने 02 फरवरी 2006 को आन्ध्रप्रदेश के अनन्तपुर जिले के बदलापल्ली गांव से किया। इसे तीन विभिन्न चरणों में पूरे देश के ग्रामीण जिलों में लागू किया गया। वर्तमान में भारत के नगरीय जिलों को छोड़कर सभी 708 ग्रामीण जिलों में लागू है। 2 अक्टूबर 2009 से इस योजना को महात्मा गांधी राष्ट्रीय ग्रामीण रोजगार गारण्टी योजना (मनरेगा) के नाम से पुकारे जाने लगा है। यह विश्व का सबसे वृहत मजदूरी कार्यक्रम है। ${ }^{4}$ मनरेगा ग्रामीण क्षेत्रों के प्रत्येक परिवार को 100 दिनों का गारण्टी युक्त रोजगार प्रदान करती है। मनरेगा में सूखा एवं अकाल, नक्सल प्रभावित क्षेत्रों तथा वनवासियों तथा आदिवासियों क्षेत्रों में रोजगार के दिन 100 से बढ़ाकर 150 दिन कर दिए हैं।

शोध प्रस्तावना- भारत की कुल जनसंख्या का 0.83 प्रतिशत उत्तराखण्ड में निवास करती है ${ }^{5}$ उत्तराखण्ड की 90 प्रतिशत जनसंख्या कृषि पर निर्भर है। ${ }^{6}$ कृषि कार्य में मौसमी तथा अदृश्य बेरोजगारी की अधिकता होने से ग्रामीणों के सामने जीविकोपार्जन समस्या उत्पन्न हो जाती है। सिडकुल की स्थापना से यहां रोजगार के अवसर बढ़ गए, किन्तु ग्रामीण क्षेत्रों में अभी भी बेरोजगारी व्याप्त है। रूद्रपुर के शहरी क्षेत्र में भले ही रोजगार अवसर बढ़े, किन्तु ये रोजगार अन्य गांवो से जीविकोपार्जन हेतु आने वाले लोगों की तुलना में, नगण्य साबित हो रहे हैं। औद्योगीकरण से रूद्रपुर की कृषि भूमि कम हो 
रही और अनेक लोग बेघर और बेरोजगार होकर दर-दर की ठोकरे खाने को मजबूर हैं। वहीं सिडकुल में 70 प्रतिशत उत्तराखण्ड के लोगों को रोजगार देने का प्रावधान है किन्तु यह कागजों तक ही सीमित है।

अतः रूद्रपुर के ग्रामीण क्षेत्रों में पलायन रोकने तथा बेरोजगारी दूर करने के लिए केन्द्र तथा राज्य सरकार द्वारा अनेक रोजगार कार्यकम चलाए जा रहे हैं। उनमें से महात्मा गांधी राष्ट्रीय ग्रामीण रोजगार गारण्टी योजना एक महत्वपूर्ण स्थान रखती है क्योंकि इसमें 100 दिनों के रोजगार की गारण्टी मिलती है जो अन्य किसी योजना में नही है। रूद्रपुर में मनरेगा की शुरूआत 1 अप्रैल 2007 से हुई। आज इसे 13 वर्ष हो चुके हैं। इस प्रकार रूद्रपुर मनरेगा के लम्बे संचालन का अनुभव रखता है।

शोध के उद्देश्य:-शोध अध्ययन के उद्देश्य निम्नांकित हैं-

1. मनरेगा से पूर्व और बाद में लाभार्थियों की आर्थिक स्थिति में आए बदलाव का अध्ययन करना।

2. मनरेगान्तर्गत में सृजित मानव दिवसों की स्थिति ज्ञात कर योगदान का आंकलन करना।

शोध विधि तथा अध्ययन क्षेत्र- शोध अध्ययन का क्षेत्र उत्तराखण्ड के उधम सिंह नगर जिले के रूद्रपुर विकास खण्ड पर आधारित है। शोधपत्र के मुख्य उद्देश्य को दृष्टिगत रखते हुए वर्णनात्मक शोध अभिकल्प का प्रयोग किया गया है। रूद्रपुर के 54 ग्राम पंचायतों के 86 राजस्व गांवो में से 10 गांवो का चयन दैव निदर्शन पद्धति की लॉटरी विधि द्वारा किया गया। इन 10 गांवो में खच्ची खमरिया, दरऊ, नारायणपुर, सैजनी, रामेश्वरपुर, कुरैया, भगवानपुर, कीरतपुर, महाराजपुर तथा इन्द्रपुर प्रमुख हैं। प्रत्येक गांव से 20-20 सूचनादाताओं का चयन स्तरीकृत दैव निदर्शन विधि द्वारा किया गया है। प्रत्येक चयनित परिवार के एक वयस्क सदस्य को चुनते हुए, कुल 200 लाभार्थियों का चयन किया गया। इन सूचनादाताओं में समाज के सभी वर्गों जैसे सामान्य, अनुसूचित जाति, अनुसूचित जनजाति तथा पिछड़े वर्ग के सदस्य शामिल है। प्रस्तुत शोध अध्ययन प्राथमिक एवं द्वितीयक दोनों समंको पर आधारित है।

शोध की सीमाएं :- शोध कार्य उधम सिंह नगर जिले के रूद्रपुर विकासखण्ड के ग्रामीण क्षेत्र तक ही सीमित है। इसमें उन गांवों का चयन किया गया है जो मनरेगा से जुड़े हैं। न्यादर्श सूचनादाताओं से प्राप्त जानकारी का प्रयोग सूचनाओं हेतु किया गया है। इसकी विश्वसनीयता उत्तरदाताओं की ईमानदारी पर निर्भर करती है। अतः प्रस्तुत शोध कार्य उधम सिंह नगर जिले के रूद्रपुर विकास खण्ड के अन्तर्गत रोजगार सृजन मे मनरेगा के योगदान तक ही सीमित है।

शोध का महत्व :- प्रस्तुत शोध के द्वारा मनरेगा से लाभार्थियों की आर्थिक स्थिति में आए बदलाव और रोजगार सृजन में मरनेगा का योगदान साबित होने से नियामक संस्थाओं, केन्द्र तथा राज्य सरकारों, नीति-निर्माताओं और शोधार्थी के लिए भविष्य मे नई रोजगारदायक योजनाओं के निर्माण मे उपयोगी साबित होगा।

किसी भी योजना की सफलता लाभार्थियों की आर्थिक स्थिति में आए सकारात्मक बदलाव से तय किया जाता है। इस हेतु मनरेगा से पूर्व और बाद में लाभार्थियों की आर्थिक स्थिति में आए बदलाव का अध्ययन निम्न प्रकार है-

1. मकान का प्रकार :- इसके अन्तर्गत मनरेगा से पहले मुख्य व्यवसाय से अर्जित आय तथा मनरेगा के बाद मुख्य व्यवसाय एवं मनरेगा से अर्जित आय के आधार पर मकानों में हुए बदलाव का मूल्यांकन किया गया है। चयनित कुल 200 उत्तरदाताओं के मनरेगा से पहले तथा बाद में हुए मकान के प्रकार का बदलाव निम्न प्रकार है :-

तालिका-1, मनरेगा से पूर्व एवं बाद में मकान का प्रकार

\begin{tabular}{|c|c|c|c|c|c|}
\hline क0सं0 & मकान का & \multicolumn{2}{|c|}{ वर्तमान } & \multicolumn{2}{c|}{ मनरेगा से पहले } \\
\cline { 3 - 6 } & प्रकार & आवृत्ति & प्रतिशत & आवृत्ति & प्रतिशत \\
\hline 1 & कच्चा & 81 & 40.50 & 144 & 72.00 \\
\hline
\end{tabular}




\begin{tabular}{|c|c|c|c|c|c|}
\hline 2 & पक्का & 87 & 43.50 & 30 & 15.00 \\
\hline 3 & मिश्रित & 32 & 16.00 & 26 & 13.00 \\
\hline & योग & $\mathbf{2 0 0}$ & $\mathbf{1 0 0}$ & $\mathbf{2 0 0}$ & $\mathbf{1 0 0}$ \\
\hline
\end{tabular}

स्रोत- प्राथमिक सर्वेक्षण

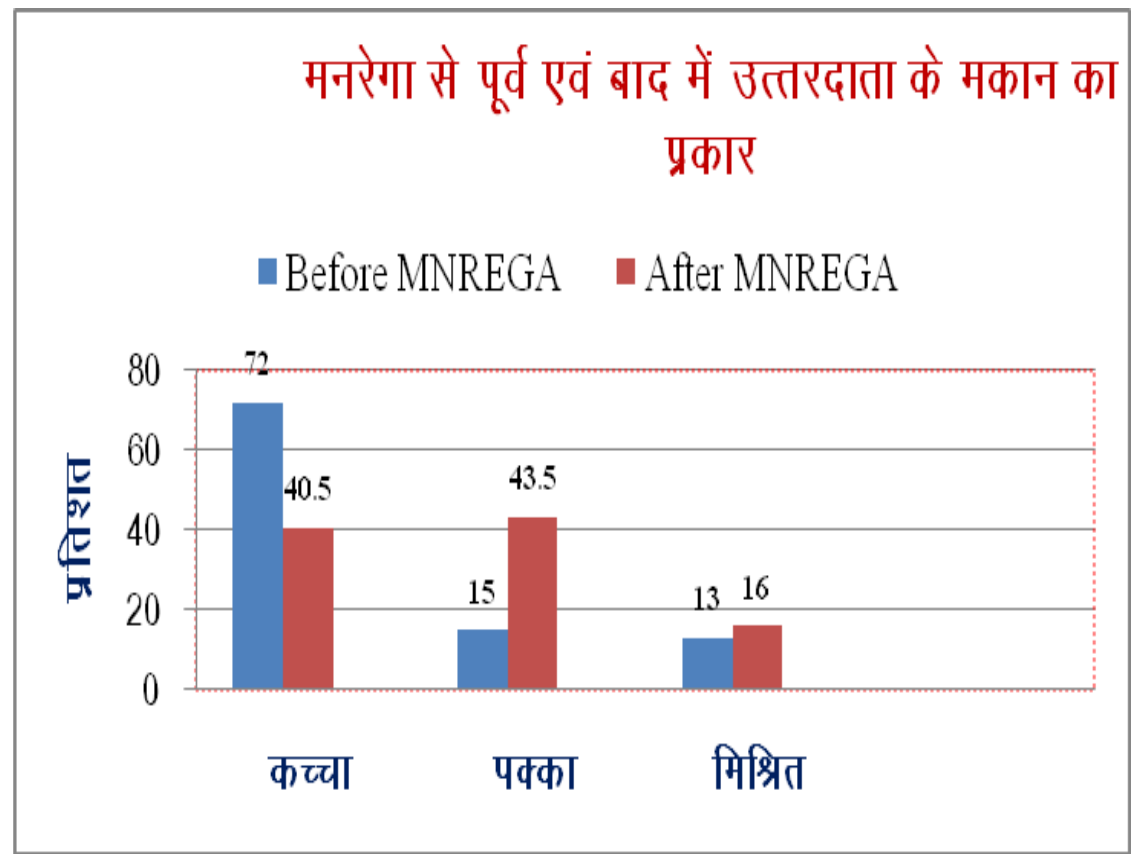

चित्र-1

तालिका 1 तथा रेखाचित्र 1 से पता चलता है कि चयनित कुल 200 उत्तरदाताओं में से मनरेगा से पहले 144 के कच्चे, 30 के पक्के तथा 26 के मिश्रित मकान हैं, जिनका प्रतिशत क्रमशः 72,15 तथा 13 है। तालिका 1 तथा रेखाचित्र 1 यह भी प्रदर्शित करता है कि मनरेगा में जुड़ने से पहले लाभार्थियों के कच्चे मकानों की संख्या अधिकतम और मिश्रित मकानों की संख्या न्यूनतम थी। इसी क्रम में पुनः तालिका 1 तथा रेखाचित्र 1 से ज्ञात होता है, कि मनरेगा के बाद, उक्त उत्तरदाताओं में से 81 के कच्चे, 87 के पक्के, तथा 32 के मिश्रित मकान हैं। जिनका प्रतिशत क्रमशः $40.50,43.50$ तथा 16 है। वर्तमान में पक्के मकानों की संख्या अधिकतम और मिश्रित मकानों की संख्या न्यूनतम है। तुलनात्मक दृष्टि से देखा जाए तो हम पाते हैं कि मनरेगा से पहले और बाद में लाभार्थियों के पक्के मकानों की संख्या में 28.50 प्रतिशत तथा मिश्रित मकानों की संख्या में 3 प्रतिशत की वृद्धि हुई है। इस प्रकार मनरेगा के बाद, कच्चे मकानों की संख्या में 31.50 प्रतिशत की कमी आयी है।

2. ईधन का प्रकार :- चयनित 200 कुल उत्तरदाताओं के मनरेगा से पहले तथा बाद में हुए ईधन के प्रकार का बदलाव इस प्रकार है-

तालिका- 2, मनरेगा से पूर्व एवं बाद में उत्तरदाता के ईधन का प्रकार

\begin{tabular}{|c|c|c|c|c|c|}
\hline क0सं0 & ईधन का प्रकार & \multicolumn{2}{|c|}{ वर्तमान } & \multicolumn{2}{|c|}{ मनरेगा से पहले } \\
\hline 1 & लकड़ी /उपले & 120 & 60.00 & 175 & 87.50 \\
\hline
\end{tabular}




\begin{tabular}{|c|c|c|c|c|c|}
\hline 2 & गैस & 80 & 40.00 & 25 & 12.50 \\
\hline & योग & 200 & 100 & 200 & 100 \\
\hline
\end{tabular}

स्रोत-प्राथमिक सर्वेक्षण

तालिका 2 तथा रेखाचित्र 2 दर्शाता है कि चयनित कुल 200 उत्तरदाताओं में से मनरेगा से पहले 175 लकड़ी/उपले द्वारा तथा 25 गैस द्वारा खाना पकाते थे, जिनका प्रतिशत क्रमशः 87.50 तथा 12.50 है। इनमें लकड़ी/उपले से खाना पकानें वालों की संख्या सर्वाधिक है। पुनः तालिका 2 तथा रेखाचित्र 2 को देखने से स्पष्ट होता है कि चयनित कुल 200 उत्तरदाताओं में से मनरेगा के बाद 120 लकड़ी/उपले तथा 80 गैस से खाना पकाते हैं। जिनका प्रतिशत क्रमशः 60 तथा 40 है। इनमें भी लकड़ी/उपले से खाना पकाने वाले व्यक्तियों की संख्या, गैस से खाना पकाने वालों की तुलना में अधिक है। तुलनात्मक रूप से ज्ञात होता है कि मनरेगा से पहले और बाद में गैस से खाना पकाने वाली की संख्या में 27.50 प्रतिशत की वृद्धि हुई है। इस प्रकार स्पष्ट हो जाता है कि मनरेगा के बाद गैस का प्रयोग करने वाले लाभार्थियों की संख्या में इजाफा हुआ है।

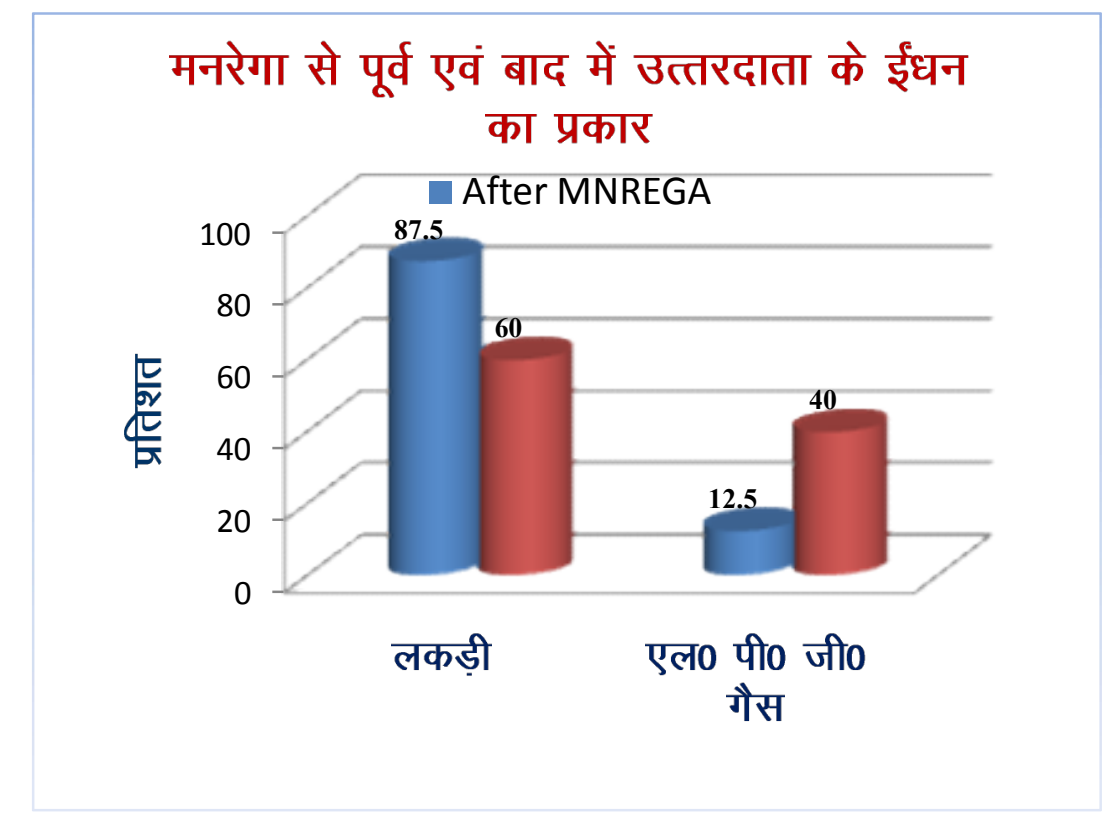

चित्र- 2

3. बच्चों की शिक्षा :- चयनित 200 उत्तरदाताओं के मनरेगा से पहले तथा बाद में बच्चों की शिक्षा में हुए बदलाव, इस प्रकार हैं-

तालिका- 3, मनरेगा से पूर्व एवं बाद में उत्तरदाता के बच्चों की शिक्षा

\begin{tabular}{|l|l|l|l|}
\hline क0सं0 & विद्यालय & वर्तमान & मनरेगा से पहले \\
\hline
\end{tabular}




\begin{tabular}{|c|c|c|c|c|c|}
\hline 1 & सरकारी विद्यालय & 125 & 62.50 & 150 & 75.00 \\
\hline 2 & प्राईवेट विद्यालय & 39 & 19.50 & 17 & 8.50 \\
\hline 3 & विद्यालय नहीं जाते & 36 & 18.00 & 33 & 16.50 \\
\hline & योग & $\mathbf{2 0 0}$ & $\mathbf{1 0 0}$ & $\mathbf{2 0 0}$ & $\mathbf{1 0 0}$ \\
\hline
\end{tabular}

स्रोत- प्राथमिक सर्वेक्षण

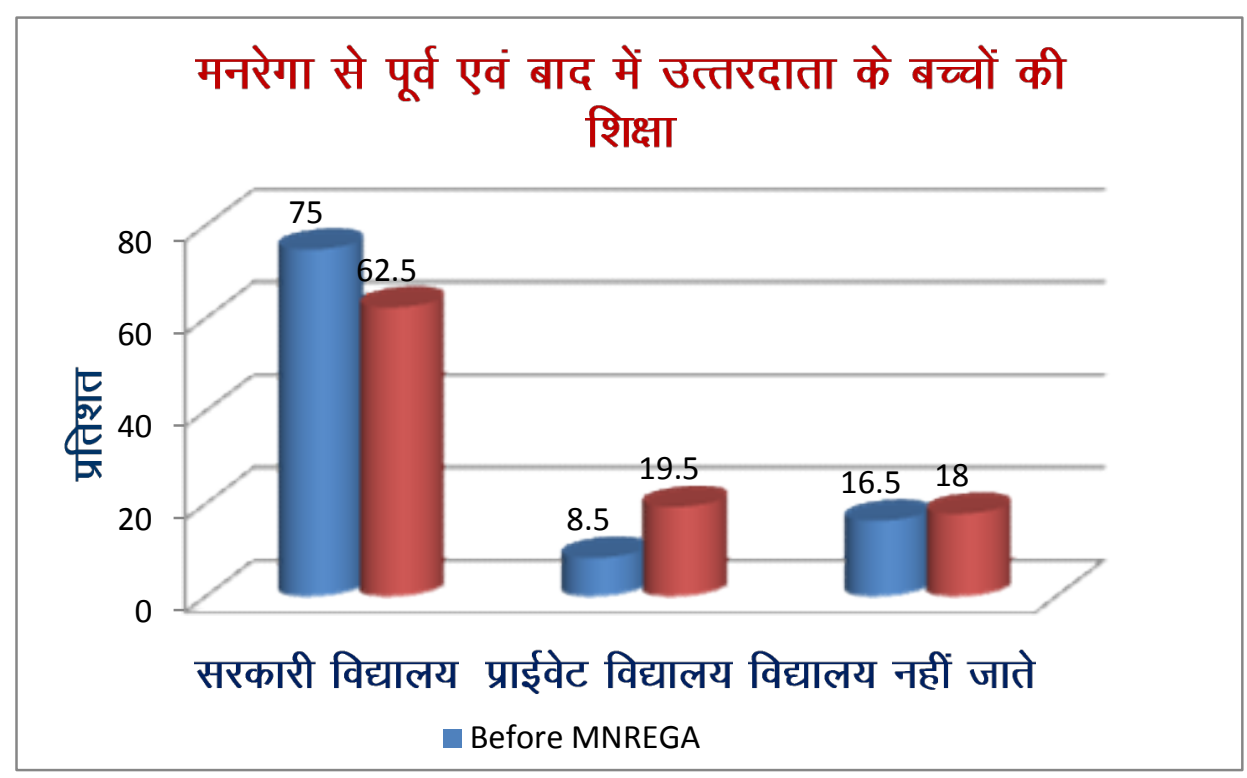

चित्र- 3

तालिका 3 तथा रेखाचित्र 3 से स्पष्ट होता है कि चयनित 200 उत्तरदाताओं में से मनरेगा से पहले 150 लाभार्थियों के बच्चे सरकारी विद्यालय में, 17 लाभार्थियों के बच्चे निजी विद्यालय में पढ़ने जाते थे तथा 33 लाभार्थियों के बच्चे, विद्यालय नहीं जाते। जिनका प्रतिशत क्रमशः $75,8.5$ तथा 16.5 है। इनमें बच्चों को सरकारी विद्यालय भेजने वालों की संख्या अधिकतम और निजी विद्यालय भेजने वालों की संख्या न्यूनतम है।

पुनः उपरोक्त तालिका तथा रेखाचित्र को देखने से पता चलता है कि 200 उत्तरदाताओं में से मनरेगा के बाद 125 लाभार्थियों के बच्चे सरकारी विद्यालय, 39 लाभार्थियों के बच्चे निजी विद्यालय में पढ़ने जाते हैं तथा 36 के बच्चे नहीं जाते। जिनका प्रतिशत क्रमशः $62.5,19.5$ तथा 18 है। इनमें भी बच्चों को सरकारी विद्यालय में भेजने वाले लाभार्थियों की संख्या सर्वाधिक है। तुलनात्मक रूप से ज्ञात होता है कि मनरेगा से पहले और बाद में अपने बच्चों को निजी विद्यालय में भेजने वाले लाभार्थियों की संख्या में 11 प्रतिशत की वृद्धि है।

4. उपचार :- चयनित कुल 200 उत्तरदाताओं के मनरेगा से पहले तथा बाद में उपचार हेतु अस्पतालों में जाने का वर्गीकरण इस प्रकार है-

तालिका- 4, मनरेगा से पूर्व एवं बाद में उत्तरदाता का उपचार 


\begin{tabular}{|c|c|c|c|c|c|}
\hline क0सं0 & \multirow{2}{*}{ अस्पताल } & \multicolumn{2}{|c|}{ वर्तमान } & \multicolumn{2}{|c|}{ मनरेगा से पहले } \\
\cline { 3 - 6 } & & आवृत्ति & प्रतिशत & आवृत्ति & प्रतिशत \\
\hline 1 & सरकारी अस्पताल & 108 & 54.00 & 128 & 64.00 \\
\hline 2 & निजी अस्पताल & 92 & 46.00 & 72 & 36.00 \\
\hline & योग & $\mathbf{2 0 0}$ & $\mathbf{1 0 0}$ & $\mathbf{2 0 0}$ & $\mathbf{1 0 0}$ \\
\hline
\end{tabular}

स्रोत- प्राथमिक सर्वेक्षण

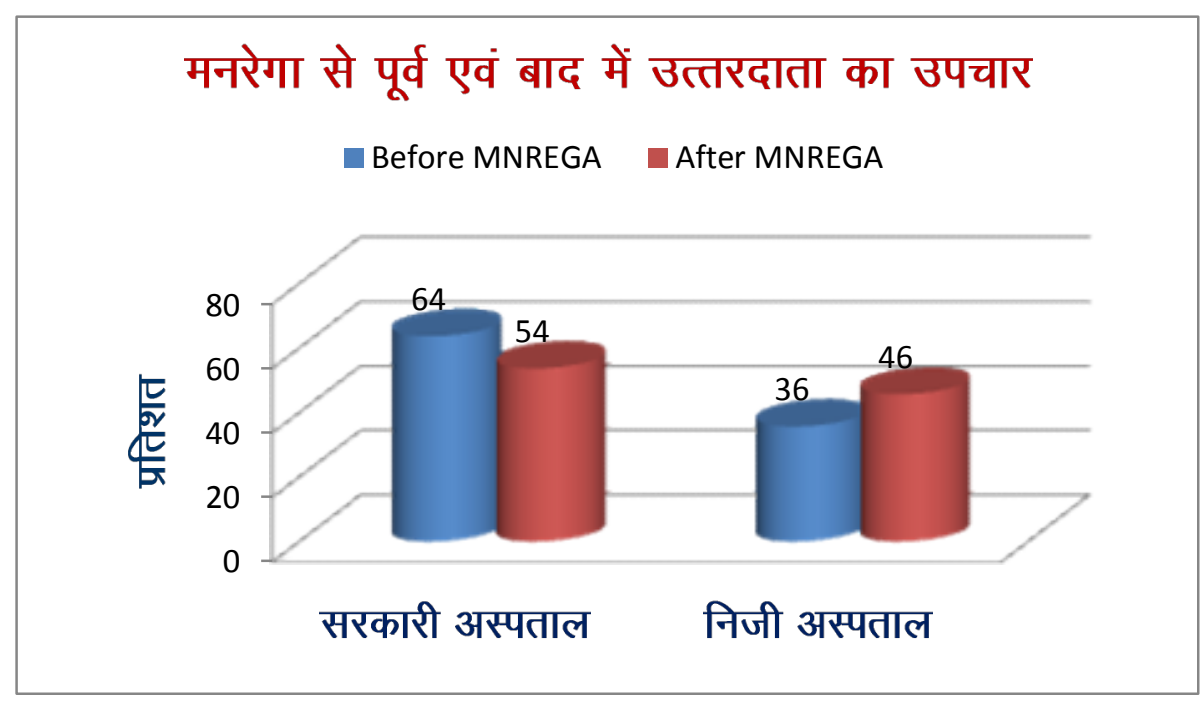

चित्र- 4

तालिका 4 तथा रेखाचित्र 4 दर्शाता है कि चयनित कुल 200 उत्तरदाताओं में से मनरेगा से पहले उपचार हेतु 128 सरकारी अस्पताल, 72 निजी अस्पताल में जाते हैं, जिनका प्रतिशत क्रमशः 64 तथा 36 है। इनमें सरकारी अस्पतालों में इलाज कराने वाले लाभार्थियों की संख्या सर्वाधिक है।

पुनः उपरोक्त तालिका तथा रेखाचित्र से स्पष्ट होता है कि वर्तमान में अर्थात मनरेगा के बाद, चयनित कुल 200 उत्तरदाताओं में से उपचार हेतु 108 सरकारी अस्पताल तथा 92 निजी अस्पतालों में इलाज कराते हैं, जिनका प्रतिशत क्रमशः 54 तथा 46 है। तुलनात्मक रूप से हमें ज्ञात होता है कि मनरेगा के बाद लाभार्थियों के निजी चिकित्सालय में इलाज हेतु जाने में 10 प्रतिशत की वृद्धि हुई है। अतः निष्कर्ष रूप में कह सकते हैं कि मनरेगा से अतिरिक्त आय अर्जन द्वारा लाभार्थी के चिकित्सा कल्याण में वृद्धि हुई है। मनरेगा द्वारा कमायी गई आय का उपयोग वे निजी अस्पतालों में उपचार हेतु कर रहे हैं।

5. आय :- मनरेगा में लाभार्थियों को आंशिक रोजगार प्राप्त होता है। मुख्य व्यवसाय लाभार्थी का कुछ और होता है, जिसमें लाभार्थी तथा उसके पारिवारिक सदस्य संलग्न रहते हैं। चयनित 200 कुल उत्तरदाताओं की कुल वार्शिक पारिवारिक आय (मुख्य व्यवसाय तथा मनरेगा से अर्जित आय) इस प्रकार है-

तालिका- 5, मनरेगा से पूर्व एवं बाद में उत्तरदाता की वार्षिक पारिवारिक आय 
Himalayan J. Soc. Sci. \& Humanities ISSN: 0975-9891

Vol. 15, (2020) 63-71

DOI: https://doi.org/10.51220/hjssh.v15i1.9

\begin{tabular}{|c|c|c|c|c|c|}
\hline क0सं० & \multirow{2}{*}{\begin{tabular}{c} 
वार्षिक पारिवारिक \\
\multirow{2}{*}{ आय (रूपये में) }
\end{tabular}} & \multicolumn{2}{|c|}{ वर्तमान } & \multicolumn{2}{c|}{ मनरेगा से पहले } \\
\cline { 3 - 5 } & आवृत्ति & प्रतिशत & आवृत्ति & प्रतिशत \\
\hline 1 & $0-10,000$ & 7 & 3.50 & 16 & 8.00 \\
\hline 2 & $10000-20,000$ & 10 & 5.00 & 12 & 6.00 \\
\hline 3 & $20000-30,000$ & 17 & 8.50 & 22 & 11.00 \\
\hline 4 & $30000-40,000$ & 14 & 7.00 & 46 & 23.00 \\
\hline 5 & $40000-50,000$ & 38 & 19.00 & 34 & 17.00 \\
\hline 6 & 50000 से अधिक & 114 & 57.00 & 70 & 35.00 \\
\hline & योग & $\mathbf{2 0 0}$ & 100 & 200 & 100 \\
\hline
\end{tabular}

स्रोत- प्राथमिक सर्वेक्षण

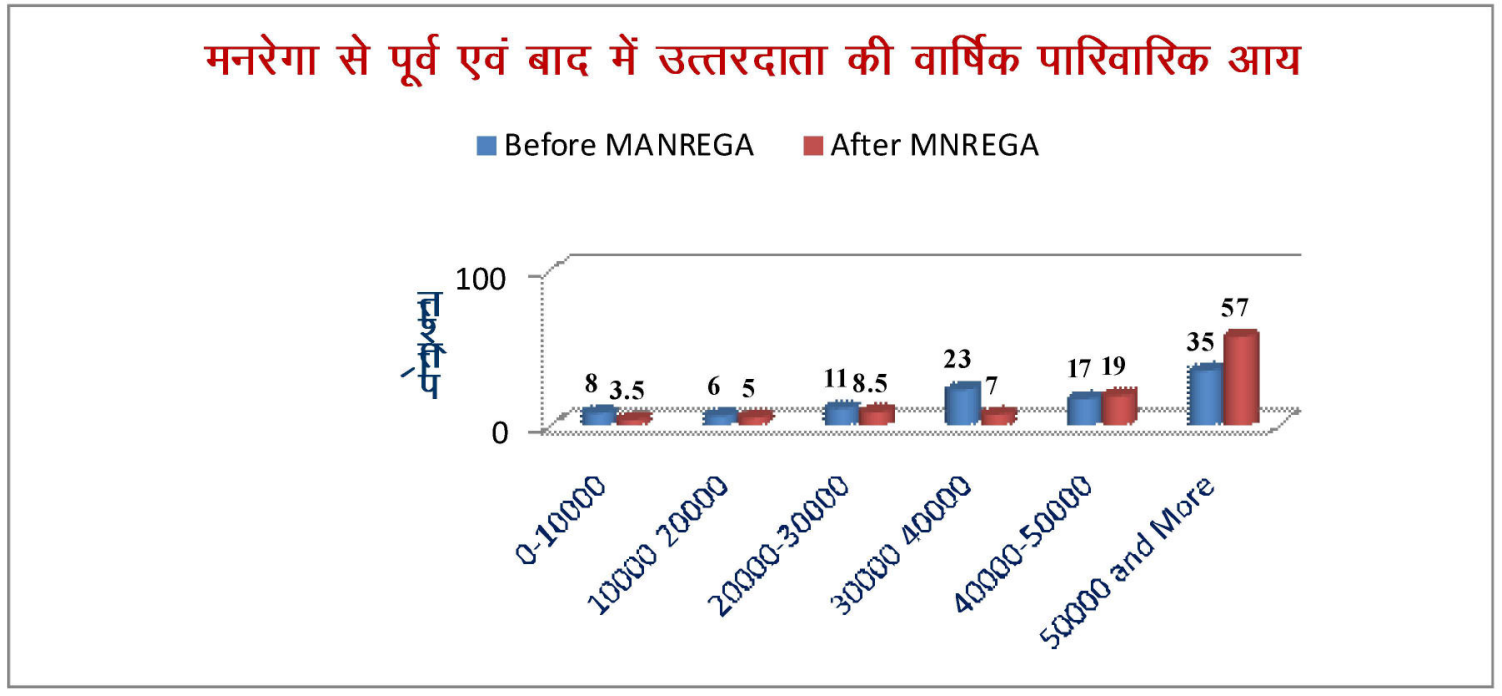

चित्र- 5

तालिका 5 तथा रेखाचित्र 5 को तुलनात्मक रूप से हम देखते हैं कि मनरेगा से पहले और बाद में 40000 से 50000 रू० वार्षिक आय तथा 50000 रू० तथा इससे अधिक वार्षिक आय वाले लाभार्थियों की संख्या में क्रमशः 2 प्रतिशत एवं 22 प्रतिशत की वृद्धि हुई है। जबकि 0-10000, 10000-20000, 20000-30000 और 30000-40000 वार्षिक आय वाले लाभार्थियों की संख्या में मनरेगा के बाद क्रमशः 4.50 प्रतिशत, 1 प्रतिशत, 2.50 प्रतिशत एवं 16 प्रतिशत की कमी आयी है।

मनरेगा में रोजगार सृजन- इस योजना को ग्रामीण बेरोजगारी दूर करने की सबसे बड़ी योजना के रूप में देखा गया है। वर्ष 2019-20 में 265.39 करोड़ मानव दिवस सृजित हुए। इसी वर्ष 5.48 करोड़ परिवारों ने मनरेगा में काम किया और प्रत्येक परिवार को वर्ष में औसतन 48.39 दिन कार्य मिला। इसी वर्ष 100 दिन का रोजगार प्राप्त परिवारों की संख्या 40,60811 है। 
योजना में लगभग 5 करोड़ से भी अधिक ग्रामीण बेरोजगारों को सालाना रोजगार मिलता है। वर्ष 2019-20 में कुल सृजित दिवसों में से 19.95 प्रतिशत अनुसूचित जाति, 18.4 प्रतिशत अनुसूचित जनजाति तथा 54.77 प्रतिशत महिलाओं द्वारा सृजित हुए। 265.39 करोड़ कुल सृजित दिवसों में से 463326 दिन के बराबर दिव्यांगों ने मनरेगा में कार्य किया। ${ }^{8}$ वर्ष 2014-15 से अब तक मनरेगा द्वारा रोजगार सृजित दिवसों का विवरण निम्नलिखित है-

\section{तालिका-6, कुल सृजित मानव दिवस, (लाख में)}

\begin{tabular}{|c|c|c|c|c|c|}
\hline वर्ष & अनुसूचित जाति & $\begin{array}{c}\text { अनुसूचित } \\
\text { जनजाति }\end{array}$ & अन्य & कुल & महिला \\
\hline $2014-15$ & 3723.519 & 2819.298 & 10075.686 & 16618.505 & 9120.401 \\
\hline $2015-16$ & 5241.974 & 4184.617 & 14087.836 & 23514.425 & 12994.009 \\
\hline $2016-17$ & 5025.994 & 4150.816 & 14401.181 & 23577.991 & 13236.866 \\
\hline $2017-18$ & 5038.79 & 4087.984 & 14246.695 & 23373.462 & 12511.115 \\
\hline $2018-19$ & 5566.225 & 4668.611 & 16560.693 & 26795.533 & 14626.627 \\
\hline $2019-20$ & 5294.404 & 4883.195 & 16361.307 & 26538.908 & 14536.247 \\
\hline $2019-20$ & 5907.985 & 5285.905 & 18389.96 & 29583.853 & 15566.554 \\
\hline
\end{tabular}

\section{स्रोत- www.nrega.nic.in, 4 जनवरी 2021 के अनुसार।}

निष्कर्ष:- मनरेगा ग्रामीणों क्षेत्रों की मौसमी बेरोजगारी दूर करने हेतु प्रारम्भ की गई है। सामान्यतया ग्रामीण लोग एक वर्ष में लगभग 150 दिन खाली रहते हैं जिसके सापेक्ष 100 दिन का रोजगार की कानूनी गारण्टी दी गई है। अतः मनरेगा को आंशिक रोजगार का साधन माना जा सकता है। रूद्रपुर विकास खण्ड में ही नहीं अपितु सम्पूर्ण देश में मनरेगा ने लोगों को अतिरिक्त रोजगार देकर अपनी महत्ता सिद्व की है। कोविड 19 जैसी वैश्विक महामारी से असंगठित क्षेत्र के करोड़ो मजदूर काम बन्द होने से बेरोजगार हो गए। लॉकडाउन के कारण लाखों लोग अपने गांवो को लौटे, ऐसे संकट के समय में मनरेगा ने रोजगार देकर अनको सहारा दिया।

\section{सन्दर्भ सूची-}

1. शर्मा, बी० डी० (1994) किसान की गरीबी का राज, नई दिल्ली प्रकाशन संस्थान, पृष्ठ 24-25

2. सेतिया सुभाष, ग्रामीण विकास का आधार-रोजगार, कुरूक्षेत्र, अंक-फरवरी 2012, पृष्ठ 9

3. Www.nrega.nic.in, 4 जनवरी 2021 के अनुसार।

4. महात्मा गांधी राष्ट्रीय ग्रामीण रोजगार गारण्टी अधिनियमः एक दशक की उपलब्धियां, ग्रामीण विकास मंत्रालय, भारत सरकार, पृष्ठ 7

5. प्रतियोगिता दर्पण, भारतीय अर्थव्यवस्था विशेषांक (2015-16) पृष्ठ 106

6. भारत 2015, प्रकाशन विभाग, सूचना एवं प्रसारण मंत्रालय, भारत सरकार, पृष्ठ 952

7. Www.nrega.nic.in, 4 जनवरी 2021 के अनुसार।

8. www.nrega.nic.in, 4 जनवरी 2021 के अनुसार। 